\title{
BIBECHANA
}

BIBECHANA

A Multidisciplinary Journal of Science, Technology

and Mathematics

ISSN 2091-0762 (online)

Journal homepage: http://nepjol.info/index.php/BIBICHANA

\section{Anomaly in energetic and structural properties of MgSn liquid alloys}

\author{
A. Kumar ${ }^{a *}$, I. S. Jha ${ }^{a}$, B. P. Singh ${ }^{b}$ \\ ${ }^{a}$ Dept. of Physics, M.M.A.M Campus Tribhuvan University, Biratnagar, Nepal. \\ ${ }^{b}$ University Department of Physics ,T.M. Bhagalpur University, Bhagalpur, Bihar, India \\ Article history: Received 1 November 2010; Revised 15 November 2010; Accepted 18 November 2010
}

\begin{abstract}
The observed asymmetry in the properties of mixing of MgSn alloy in molten state is successfully explained on basis of the quasi-lattice model. It has been utilized to determine the free energy of mixing, entropy of mixing, heat of mixing, the concentration- concentration structure factor in long wave-length limit $[\operatorname{Scc}(0)]$ and the Warren Cowley short range order parameter $\left(\alpha_{1}\right)$ of $\mathrm{MgSn}$ alloy in molten state at $1073 \mathrm{~K}$. The analysis suggests that heterocordiantion leading to the formation of chemical complex $\mathrm{Mg}_{2} \mathrm{Sn}$ is likely to exist in the melt but is of a weakly interacting in nature. The interaction energies between the species of the melt are found to depend considerably on temperature and the alloy is more ordered towards $\mathrm{Mg}$ rich region
\end{abstract}

Keywords: Quasi-lattice model; Binary alloys; Short range order parameter; Asymmetry

\section{Introduction}

A large number of binary alloys specially the compound forming alloys exhibit interesting behaviour as a function of concentration as regards the thermodynamic [1] and electric properties $[2,3]$. The properties of mixing are not symmetrical about the equiatomic compositiondeviating maximally from those of ideal alloys. Some of the alloys also depict metal - non metal transition across narrow band of concentration. The liquidus lines are usually S-shaped and the heat of mixing and excess free energy of mixing are large negative quantities at one or other concentrations [4- 6]. The anomalous behaviour of these liquid alloys still demands extensive theoretical investigation.

The properties of mixing of $\mathrm{MgSn}$ alloy is of interest as various properties of it show anomalous behaviour as the function of concentration. The liquidus line is endowed with two eutectics in the terminal region of concentration with the bump around the stoichiometric

\footnotetext{
* Corresponding author: Ashok Kumar, Dept. of Physics, M.M.A.M Campus Tribhuvan University, Biratnagar, Nepal, Email :ashok_kumar601@yahoo.com
} 
composition of $\mathrm{Mg}_{2} \mathrm{Sn}$. The large value of viscosity [7] and the analysis of the radial distribution function [8] indicate that unlike atoms attract, with the interaction being greatest at the composition $\mathrm{Mg}_{2} \mathrm{Sn}$.The properties of mixing show asymmetry around the equiatomic composition for $\mathrm{MgSn}$ alloy also.

There are so many models such as pseudo potential theory $[9,10]$, hard sphere model [11- 14], the conformal solution model [15] etc. to study the alloying behaviour of liquid alloy. But in the present investigation we have used quasi-lattice model developed by Bhatia and Singh as it is successful in investigating both the thermodynamic properties and microscopic structure $[16,17]$. On the basis of this model we have calculated the thermodynamic quantities such as free energy of mixing, excess entropy of mixing, and heat of mixing. To understand the microscope structure of the alloy we have calculated concentration-concentration fluctuation in the long wave-length limit $\left[\mathrm{S}_{\mathrm{cc}}(0)\right]$ and the short range order parameter $\left[\alpha_{1}\right]$. The phenomena of compound formation and segregation can easily be interpreted through the study of $S_{c c}(0)$ and $\alpha_{1}$ [18-26].

In section 2 the general formulation of quasi-lattice model are summarised to simple expressions. Section 3 deals with the results and discussions. Section 4 provides the conclusion.

\section{Theory}

The quasi-lattice chemical model envisages the existence of chemical complex $\left[\mathrm{A}_{\mu} \mathrm{Bv}\right]$ where $A$ and $B$ are constituent species and $\mu$ and $v$ are small integers, $\mu A+v B \rightleftharpoons A \mu B v$.

The grand partition function is solved by assuming that the energy of a given nearest bond is different if it belongs to the complex than if it does not. With this consideration the expression for excess free energy of mixing comes out to be

$$
\mathrm{G}_{\mathrm{M}}^{\mathrm{XS}}=\mathrm{NK}_{\mathrm{B}} \mathrm{T} \int_{\mathrm{O}}^{\mathrm{c}} \ln \gamma \mathrm{dc}
$$

where $\mathrm{N}$ is the total no. of atom in the alloy ' $\mathrm{c}$ ' the concentration of atom A $\mathrm{T}$ the absolute scale temp., $K_{B}$ the Boltzman constant and $\gamma$ is the ratio of the activity co-efficient of atom A to B.

The solution of equation (1) leads to

$$
\mathrm{G}_{\mathrm{M}}^{\mathrm{XS}}=\mathrm{N}\left[\mathrm{c}(1-\mathrm{c}) \omega+\phi_{\mathrm{AB}} \Delta \omega_{\mathrm{AB}}+\phi_{\mathrm{AA}} \Delta \omega_{\mathrm{AA}}+\phi_{\mathrm{BB}} \Delta \omega_{\mathrm{BB}}\right]
$$

where $\omega$ 's are ordering energy and $\phi$ is some constant given by

$\mathrm{K}_{\mathrm{B}} \mathrm{T} \phi_{\mu, v}=\Delta \omega_{\mathrm{AB}}[2 \beta(\mu+1, v)-2 \beta(\mu, v+1)+\beta(2 \mu, 2 v-1)+\beta(2 \mu-1,2 v)]+\Delta \omega_{\mathrm{AA}}[\beta(2 \mu-2,2 v+1)$

$$
-2 \beta(\mu, v+1)+\Delta \omega_{\text {Bв }}[2 \beta(\mu+1, v)-\beta(2 \mu+1,2 v-2)]
$$

for Fe-Si liquid alloy

$$
\begin{aligned}
& \mathrm{A}=\mathrm{Mg}, \quad \mathrm{B}=\mathrm{Sn}, \quad \mu=2, \quad v=1 \\
& \phi_{\mathrm{AB}}(\mathrm{c})=\left[\frac{1}{6} \mathrm{c}+\mathrm{c}^{2}-\frac{5}{3} \mathrm{c}^{3}+\frac{1}{2} \mathrm{c}^{4}\right] \\
& \phi_{\mathrm{AA}}(\mathrm{c})=\left[-\frac{1}{4} \mathrm{c}+\frac{1}{2} \mathrm{c}^{2}-\frac{1}{4} \mathrm{c}^{4}\right] \\
& \phi_{\mathrm{BB}}(\mathrm{c})=0
\end{aligned}
$$

Using eqn. (4), (5) and (6) in eqn. (2),

$$
\mathrm{G}_{\mathrm{M}}^{\mathrm{XS}}=\mathrm{N}\left[\omega \mathrm{c}(1-\mathrm{c})+\Delta \omega_{\mathrm{AB}}\left(\frac{1}{6} \mathrm{c}+\mathrm{c}^{2}-\frac{5}{3} \mathrm{c}^{3}+\frac{1}{2} \mathrm{c}^{4}\right)+\Delta \omega_{\mathrm{AA}}\left(-\frac{1}{4} \mathrm{c}+\frac{1}{2} \mathrm{c}^{2}-\frac{1}{4} \mathrm{c}^{4}\right)\right]
$$

The free energy of mixing of complex forming binary alloy

$$
\mathrm{G}_{\mathrm{M}}=\mathrm{G}_{\mathrm{M}}^{\mathrm{XS}}+\mathrm{RT}[\mathrm{c} \ln \mathrm{c}+(1-\mathrm{c}) \ln (1-\mathrm{c})]
$$

where $\mathrm{R}$ is universal gas constant. 
The excess entropy of mixing is given by

$$
\begin{gathered}
\mathrm{S}_{\mathrm{M}}^{\mathrm{XS}}=-\left(\frac{\mathrm{dG}_{\mathrm{M}}^{\mathrm{XS}}}{\mathrm{dT}}\right)_{\mathrm{P}} \\
\mathrm{S}_{\mathrm{M}}^{\mathrm{XS}}=-\mathrm{N}\left[\frac{\mathrm{d} \omega}{\mathrm{dT}} \phi(\mathrm{c})+\frac{\mathrm{d}}{\mathrm{dT}}\left(\Delta \omega_{\mathrm{AB}}\right) \phi_{\mathrm{AB}}(\mathrm{c})+\frac{\mathrm{d}}{\mathrm{dT}}\left(\Delta \omega_{\mathrm{AA}}\right) \phi_{\mathrm{AA}}(\mathrm{c})+\frac{\mathrm{d}}{\mathrm{dT}}\left(\Delta \omega_{\mathrm{BB}}\right) \phi_{\mathrm{BB}}(\mathrm{c})\right]
\end{gathered}
$$

where $\phi(c)=c(1-c)$.

$$
\mathrm{S}_{\mathrm{M}}=\mathrm{S}_{\mathrm{M}}^{\mathrm{xs}}-\mathrm{R}[\mathrm{c} \ln \mathrm{c}+(\mathrm{c}-1) \ln (\mathrm{c}-1)
$$

From standard thermodynamic relations, the heat of mixing

$$
\mathrm{H}_{\mathrm{M}}=\mathrm{G}_{\mathrm{M}}^{\mathrm{XS}}+\mathrm{TS}_{\mathrm{M}}^{\mathrm{XS}}
$$

To understand the nature of atomic order in the binary liquid alloy it is instructive to study the behaviour of the long wave-length limit of the concentration-concentration structure factor $\left[S_{\mathrm{cc}}(0)\right](16,17)$ given as

$$
\mathrm{S}_{\mathrm{cc}}(\mathrm{o})=\mathrm{NK}_{\mathrm{B}} \mathrm{T} /\left(\frac{\partial^{2} \mathrm{G}_{\mathrm{M}}}{\partial \mathrm{c}^{2}}\right)_{\mathrm{T}, \mathrm{P}, \mathrm{N}}
$$

where $\mathrm{G}_{\mathrm{M}}$ is free energy of mixing.

Using eqn. (7), (8) and (11)

$$
\mathrm{S}_{\mathrm{cc}}(\mathrm{o})=\frac{\mathrm{c}(1-\mathrm{c})}{1+\frac{\mathrm{c}(1-\mathrm{c})}{\mathrm{K}_{\mathrm{B}} \mathrm{T}}\left[-2 \omega+\Delta \omega_{\mathrm{AB}} \phi_{\mathrm{AB}}^{\prime \prime}+\Delta \omega_{\mathrm{AA}} \phi_{\mathrm{AA}}^{\prime \prime}+\Delta \omega_{\mathrm{BB}} \phi_{\mathrm{BB}}^{\prime \prime}\right]}
$$

where $\phi_{i, j}^{\prime \prime}=\frac{d^{2} \phi_{i, j}}{{d c^{2}}^{2}}(i, j=A, B)$

The experimental determination of $\mathrm{S}_{\mathrm{cc}}(0)$ poses more difficulty, but it can be determined from measured activity data and it is usually considered to be experimental values. The warrenCowley short-range order parameter $\left(\alpha_{1}\right)[26,27]$. Can estimated from the knowledge of $S_{c c}(0)$ as

$$
\alpha_{1}=\frac{(\mathrm{S}-1)}{\mathrm{S}(\mathrm{z}-1)+1}, \quad \mathrm{~S}=\frac{\mathrm{S}_{\mathrm{cc}}(0)}{\mathrm{S}_{\mathrm{cc}}^{\text {id }}(0)}
$$

$\mathrm{S}_{\mathrm{cc}}^{\mathrm{id}}(0)=\mathrm{c}(1-\mathrm{c})$ and $\mathrm{z}$ is co-ordination number $\mathrm{z}=10$ has been taken for our calculation.

\section{Results and Discussions}

\subsection{Free energy of mixing}

The energy parameters used for the calculations of the free energy of mixing for MgSn liquid alloys are has been determined from experimental values of $G_{M}(1)$ in the concentration range from 0.1 to 0.9 by the method of successive approximation. The coefficient $\left(\Delta \omega_{\mathrm{BB}}\right)=0$ since $v=1$. The remaining two parameters are found to be

$$
\frac{\omega}{\mathrm{K}_{\mathrm{B}} \mathrm{T}}=-5.0, \quad \frac{\Delta \omega_{\mathrm{AB}}}{\mathrm{K}_{\mathrm{B}} \mathrm{T}}=-0.86 \quad \text { and } \quad \frac{\Delta \omega_{\mathrm{AA}}}{\mathrm{K}_{\mathrm{B}} \mathrm{T}}=-0.47
$$

Thus equation (7) and (8) are used to compute free energy of mixing $\left(\mathrm{G}_{\mathrm{M}} / \mathrm{RT}\right)$ of $\mathrm{MgSn}$ liquid alloy.

The theoretical and experimental values of free energy of mixing for MgSn liquid alloy is shown in figure 1 . The theoretical result is in good agreement with experimental values in the terminal regions of concentrations $\mathrm{c}_{\mathrm{Mg}}=0.1$ to 0.3 and 0.8 to 0.9 , in which the liquidus line is endowed with eutectics. But the theoretical results do not agree so well with experimental values in the intermediate region of concentration $\mathrm{c}_{\mathrm{Mg}}=0.3$ to 0.7 in which the liquidus line shows sharp 
rise with the bump at $\mathrm{c}_{\mathrm{Mg}}=0.66$. The experimental value shows value of $\mathrm{G}_{\mathrm{M}} / \mathrm{RT}=-2.316$ at $\mathrm{c}_{\mathrm{Mg}}=$ 0.6 but our theoretical result shows minimum $\mathrm{G}_{\mathrm{M}} / \mathrm{RT}=-2.0714$ at $\mathrm{c}_{\mathrm{Mg}}=0.51$. The theoretical analysis of free energy of mixing shows that in liquid state $\mathrm{MgSn}$ is a weak interacting system.

\subsection{Entropy of mixing}

To determine the excess entropy mixing for $\mathrm{MgSn}$ liquid alloy we need the temperature derivatives of interaction parameters in Eq. (9). The observed values of $S_{M}^{S X}$ are used to obtained the temperature derivative by successive approximation method. It is notice that the temperature derivative of $\omega_{\mathrm{AA}}$ is negligibly small so we set the $\frac{\mathrm{d}}{\mathrm{dT}}\left(\omega_{\mathrm{AA}}\right)=0$ and also $\frac{\mathrm{d}}{\mathrm{dT}}\left(\omega_{\mathrm{BB}}\right)=0$. The remaining parameters are found to be

$$
\frac{1}{\mathrm{~K}_{\mathrm{B}}} \frac{\mathrm{d} \omega}{\mathrm{dT}}=-0.2 \quad \frac{1}{\mathrm{~K}_{\mathrm{B}}} \frac{\mathrm{d} \omega_{\mathrm{AB}}}{\mathrm{dT}}=-0.03
$$

The excess entropy of mixing is calculated using Eqs.(9) and (9a) to evaluate $S_{M}$. The theoretical and experimental values of $\frac{S_{M}}{R}$ against $c_{M g}$ are plotted in figure 1 . The theoretical and experimental values are in excellent agreement. Both show minimum at $\mathrm{c}_{\mathrm{Mg}}=0.6$.

\subsection{Heat of mixing}

The heat of mixing for MgSn liquid alloy has been computed from Eq. (10) using the same values of $\frac{d \omega}{d T}$ and $\frac{d \omega_{A B}}{d T}$. The plot of $\frac{H_{M}}{R T}$ versus $c_{M g}$ at $1073 \mathrm{~K}$ is depicted in figure 1 . The theoretical and experimental values are in good agreement. The theoretical and experimental

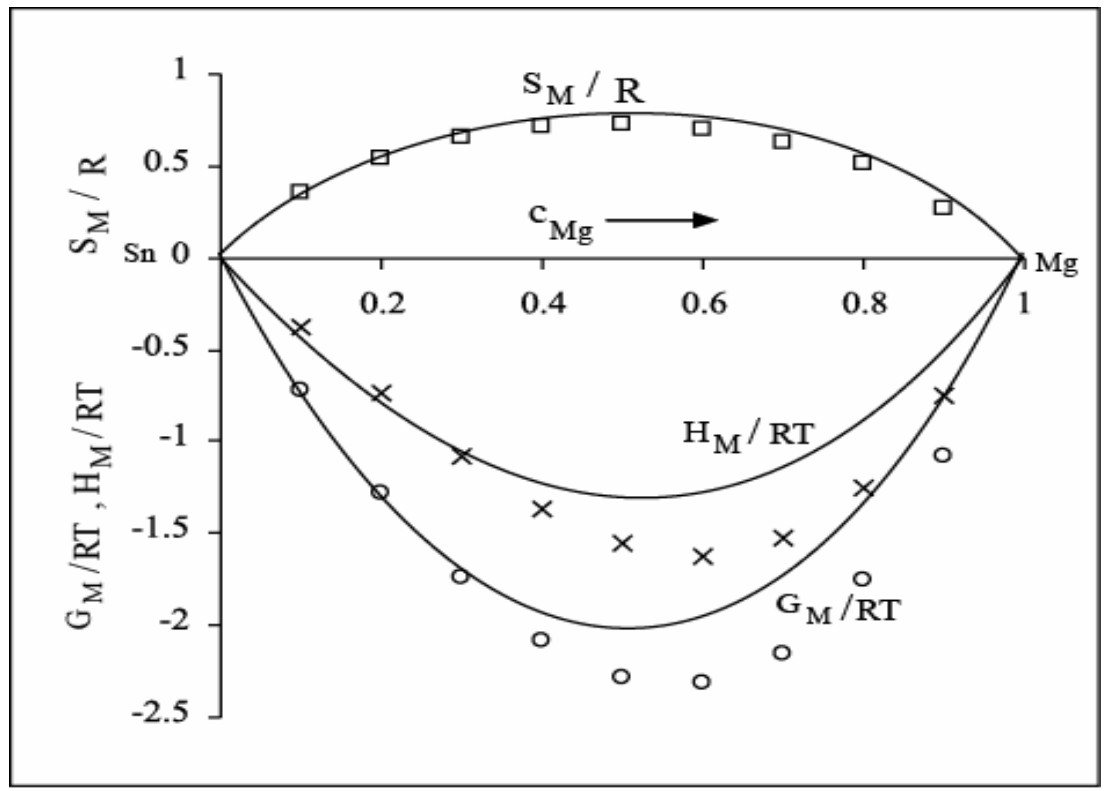

Figure: Free energy of mixing $\left(\mathrm{G}_{\mathrm{M}} / \mathrm{RT}\right)$, heat of mixing $\left(\mathrm{H}_{\mathrm{M}} / \mathrm{RT}\right)$ and entropy of mixing $\left(S_{M} / R\right.$ ) verses $c_{M g}$ (concentration of $\mathrm{Mg}$ ) for MgSn liquid alloy at $1073 \mathrm{~K}$. [- $]$ theoretical, [oooo] , [ xxx] and [0] ] experimental [1]. 
results show almost the same nature as shown by the free energy of mixing. Again the theoretical results are good agreement in terminal regions of concentration but do not agree so well in the intermediate region of concentration.

\subsection{The concentration-concentration structure factor $\left[S_{c c}(0)\right]$ and short range order parameter $\left(\alpha_{1}\right)$}

The theoretical values of $\mathrm{S}_{\mathrm{cc}}(0)$ computed from Eq.(12) using the same energy parameters and experimental values along with the ideal values are shown in figure 2 . The theoretical values of $S_{c c}(0)$ are in good agreement with the experimental values. $S_{c c}(0)$ can be used to understand the nature of atomic order in binary alloys. At the given composition if $S_{c c}(0)$ $<\mathrm{S}_{\mathrm{cc}}^{\mathrm{id}}(0)$, ordering in liquid alloy is excepted and if $\mathrm{S}_{\mathrm{cc}}(0)>\mathrm{S}_{\mathrm{cc}}^{\mathrm{id}}(0)$, there is tendency of segregation. We find that there is a clear dip at $\mathrm{c}_{\mathrm{Mg}}=0.7$ showing that $\mathrm{Mg}_{2} \mathrm{Sn}$ is most ordered at this concentration.

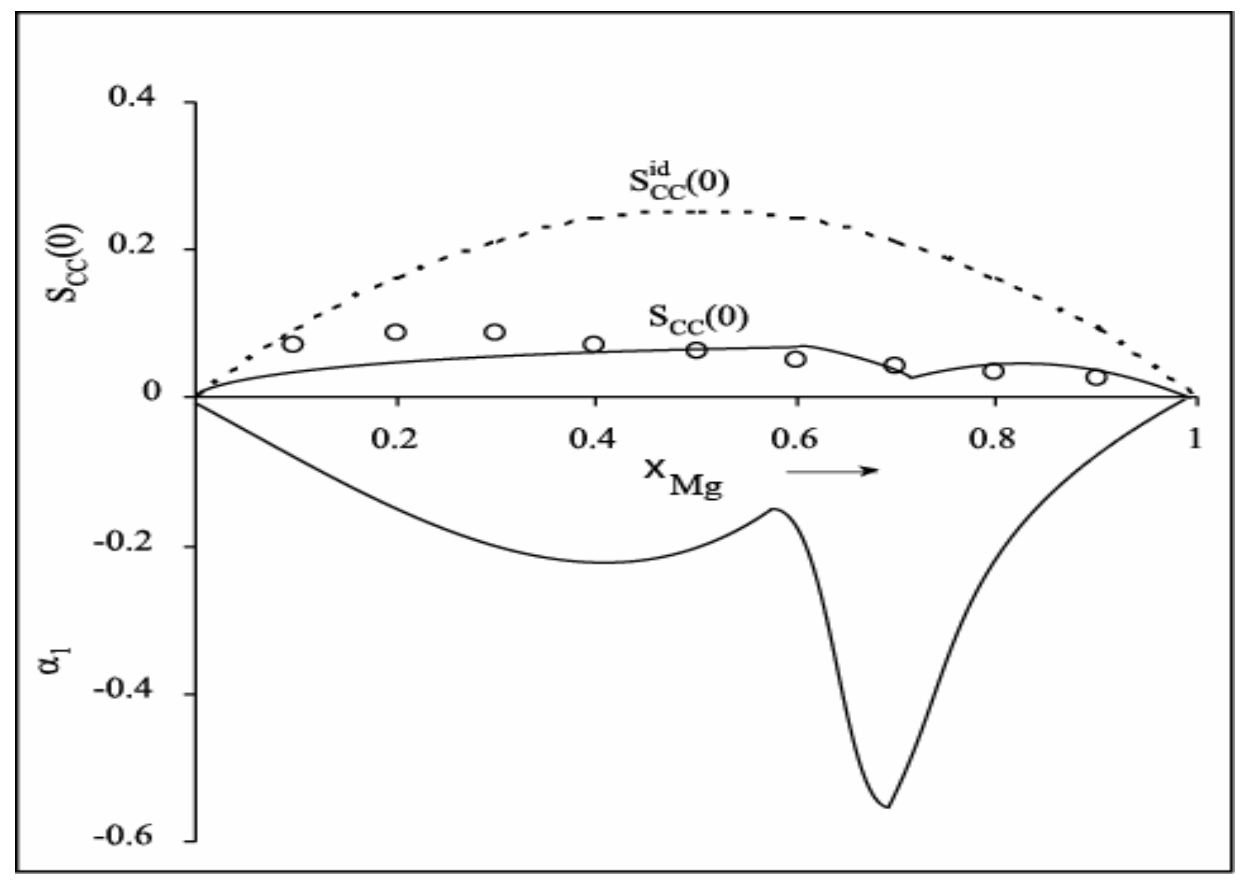

Figure 2: Upper part concentration fluctuation in long wave-length limit $\left[\mathrm{S}_{\mathrm{cc}}(0)\right]$ for $\mathrm{MgSn}$ liquid alloy at $1073 \mathrm{~K}$ at different concentrations of Mg. [- ] theoretical, [oooo] experimental. Lower part short range order parameter $\left(\alpha_{1}\right)$ versus $\mathrm{c}_{\mathrm{Mg}}$.

The knowledge of $\alpha_{1}$ provides an immediate insight into the nature of the local arrangement of atoms in the mixture. The minimum possible value of $\alpha_{1}$ is -1 and it implies complete ordering of unlike atom paring at nearest atoms. On the other hand the maximum value of $\alpha_{1}$ is +1 , which implies complete segregation leading to the phase separation and $\alpha_{1}=0$ corresponds to a random distribution of atoms. Figure 2 show that $\alpha_{1}$ is negative throughout showing that $\alpha_{1} \mathrm{MgSn}$ is an ordered system of unlike atom pairing at all concentration. $\alpha_{1}$ is found to be minimum at $\mathrm{c}_{\mathrm{Mg}}=$ 0.7 . 


\section{A. Kumar et al. / BIBECHANA 7 (2011) 33-38 : BMHSS}

\section{Conclusion}

In present work, we have used quasi-lattice model and calculated the pair wise interaction energy for $\mathrm{MgSn}$ liquid alloy at $1073 \mathrm{~K}$. These were used to estimate the thermodynamic properties and concentration fluctuation in long wavelength limit of $\mathrm{MgSn}$ liquid alloy. Computed values of $S_{\mathrm{cc}}(0)$ and $\alpha_{1}$ suggest that there is a tendency towards unlike atom pairing $(\mathrm{Mg}-\mathrm{Sn})$ over the whole range of concentration. Our theoretical analysis shows that the complex $\mathrm{Mg}_{2} \mathrm{Sn}$ is present in the molten state of $\mathrm{MgSn}$ alloy.

\section{References}

[1] R. Hultgren P. D. Desai, D. T. Hawkins, M. Gleisser and K. K. Kelley. Selected values of the Thermodynamic Properties of Binary alloys. ASM, Metal park ohio, 1973 (871).

[2] G. Busch, H. N. Guntnerodt, in Ehrenreich, F. Seitz, D. Turnball (Eds) solid state Physics, Academic, New York ,29 (1974) 1235.

[3] S. Takeuchi, K. Murakami, Sci. Rep. RITU, 25 (1974).

[4] P. Chiux and H. Rupersberg, J. Phys (Les Ulis. Fr.) ,C8 (Lam4) 41 (1980) 145.

[5] P. Lamperter, W. Martin and S. Steeb, J. Non Cryst. Solids, 61 (1984) 279.

[6] B. C. Anusionwu, Pramana, J. Phys., 67 (2006) 319.

[7] V.M. Glazov, S.N. Chizhevskaya and N.N. Glagoleva, Liqs. Semicondutors (New York Paenum), (1969)277.

[8] S.Steeb and H. Entress, Z. Metallik, 57(1966)803.

[9] W. A. Harrison Pseudo potential in the theory of metals, Benjami New York, (1966).

[10] V. Hein, Solid state physics ,Academic New York, (1970).

[11] E. Theile, J. Chem. Phys, Lett., 39 (1963) 474.

[12] J. Libowitz, Phys. Rev. A,133 (1964) 895.

[13] T. E. Faber, Introduction to the theory of liquid Metals Cambridge University Press, Cambridge, (1972).

[14] M. Shimoji, Liquid Metals ,London Academy London ,(1977).

[15] H. C. Longuet Higgins, Proc. Roy. Soc., A 205 (1951) 247.

[16] A. B. Bhatia and R. N. Singh (Phys. Chem Liqs., 11 (1982) 343.

[17] A. B. Bhatia and R. N. Singh (Phys. Chem. Liqs., 13 (1984) 177.

[18] D. Adhikari, I.S.Jha and B.P.Singh, Physica B, 405(2010)1861.

[19] A. B. Bhatia, W. H. Hargrove and N. H. March, J. Phys. ,C6 (1973) 621.

[20] J. A. Alonso, and N. H. March Physica B,114 (1982) 67.

[21] E. A. Guggenheim, Mixtures, Oxford University Press, Oxford, (1952).

[22] N. K. P. Singh, I. K. Mishra and V. N. Singh J. Phys. Conds. Matter ,2 (1990) 8445.

[23] R. N. Singh and L. C. Prasad Phys. Chem. Liqs. ,22 (1990)1.

[24] S. K. Chatterjee and L. C. Prasad, Indian J. Pure App. Phys., 42 (2004), 279.

[25] N. K. P. Singh, R. N. Singh and R. B. Choudhary, J. Phys. Conds. Matter, 3 (1991) 5345.

[26] J. M. Cowley, Phys. Rev. 77 (1950) 667.

[27] B. E. Warren X-ray Diffraction, Addison Wesley, Reading M. A. ,(1969)p. 227. 